\title{
Nothing is sacred on the Philippine smoking front
}

Half a century ago, a noted Filipino priest, $\mathrm{Fr}$ Horacio dela Costa, SJ, wrote that there are two aspects that define the Filipino people: their songs and their faith.

If you look at the world through the eyes of a farmer, life is a little harsh: typhoons frequently wreak havoc on crops. From the point of view of a city dweller, life is harsher still, what with the daily traffic jams, among other things.

The Philippines in the time of Fr dela Costa and the Philippines in the runup to the year 2000 is still much the same country: too much factionalism, too little of the sense of nationhood. And Filipinos still show they are one nation when they live it up through song and dance, and when they still worship the same God today, perhaps with more fervour because $\mathrm{He}$ makes a difference in a country with more than its share of challenges.

One of the finest illustrations of the Filipinos' faith is the presentation of petitions to the Son of God through Mary, the Mediatrix, Queen of Heaven and Earth. And the best example of this that one can present is the throng of people every Wednesday in Baclaran church in Paranaque. The whole place is charged with the electricity of hope, a priceless commodity in the Philippines.

To someone who has studied the marketing strategy of tobacco manufacturing giants that operate in the Philippines, it comes as a shock when one sees that Hope and Winston cigarettes are sold using the prayer highway that Mother Mary has especially paved for Filipinos.

This cigarette manufacturer (Fortune Tobacco) has ingeniously made use of the Filipinos' faith in Mother Mary by dishing out calendars with the face of Mary (figure 1), with their products cleverly appended at the bottom of the poster-calendar. The face of Mary in Baclaran church is the same face that graces the calendar.

The harried modern-day Filipino who finds time every night to pray the rosary will not think twice of using the calendar that sells the evil weed as the frontispiece of a makeshift altar!

If this were done to the leader of a countrysay, President Clinton being shown indirectly endorsing Joe Camel —one can be sure that the producers of the material would at least receive a call from the White House. The painful reality is that it would seem that the people who can control this marketing strategy are helpless in the face of the dictum that if it is legal to sell, it is legal to advertise.

The Philippines is also host to the Marlboro Tour every year. Dozens of horse-legged cyclists compete in this bicycle race. This does not come as a shock anymore, because cigarette manufacturers have waved the flags of sports, good health, good living and culture to

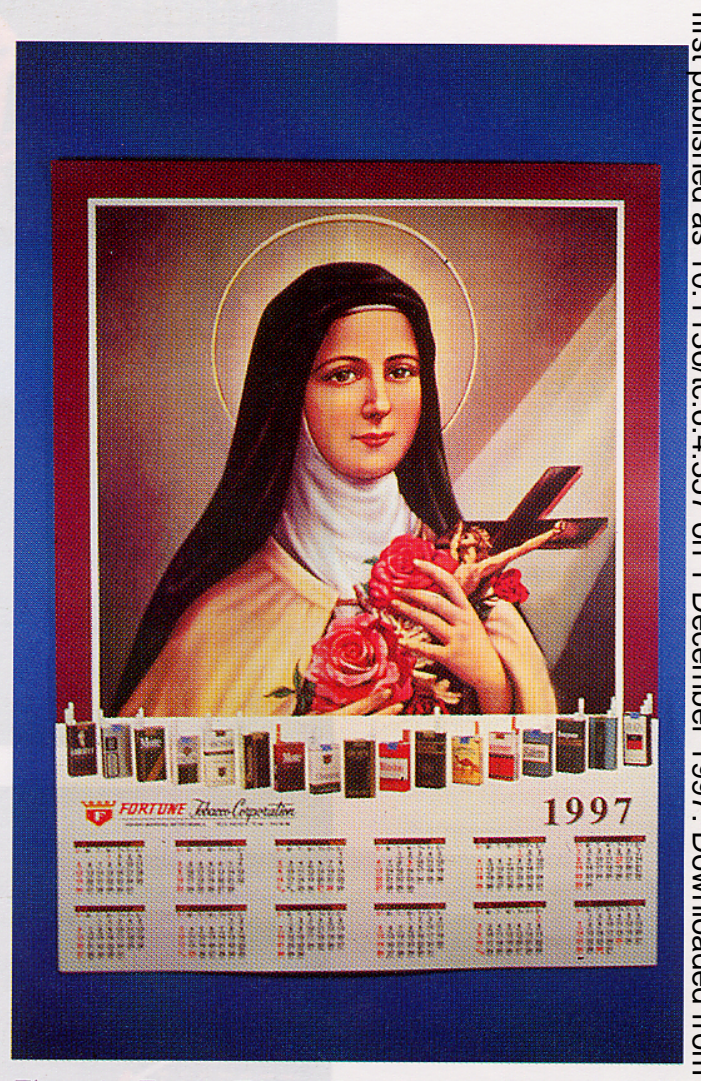

Figure 1 Fortune Tobacco Company's 1997 "Madonna" calendar.

go for the jugular of the Filipino smoker and would-be smoker.

But religious worship? This practice of using religious images as visuals in marketing tools is by far the most cynical and profane.

The uneducated consumer, upon seeing the serene face of Mother Mary, would by inference think that smoking also lends serenity to one's life. The Filipino teenager, when offered his first "stick", would think that it is all right to puff because he remembers seeing the same cigarette pack on his family's altar!

To make matters worse, the cigarette maker $\stackrel{N}{\circ}$ also uses pin-up models for those less inclined $\tilde{O}$ to religious worship (figure 2). You see $\underset{\omega}{\mathfrak{\omega}}$ half-clothed women in their most alluring poses. That's the only difference. The paper 0 weight is the same, the products at the bottom of the layout are the same products that underline the face of the Virgin Most Pure.

No, retch is not the right reaction. A deep-seated feeling of helplessness, mixed with a liberal dose of rage, may be the more appropriate reaction of one who would care to take a second look.

Violated for three-and-a-half centuries by Western colonisers, the Filipinos have a coping mechanism: humour-megadoses of it. It is very possible that Filipinos do not take this slight on their Mother Mary seriously because, 

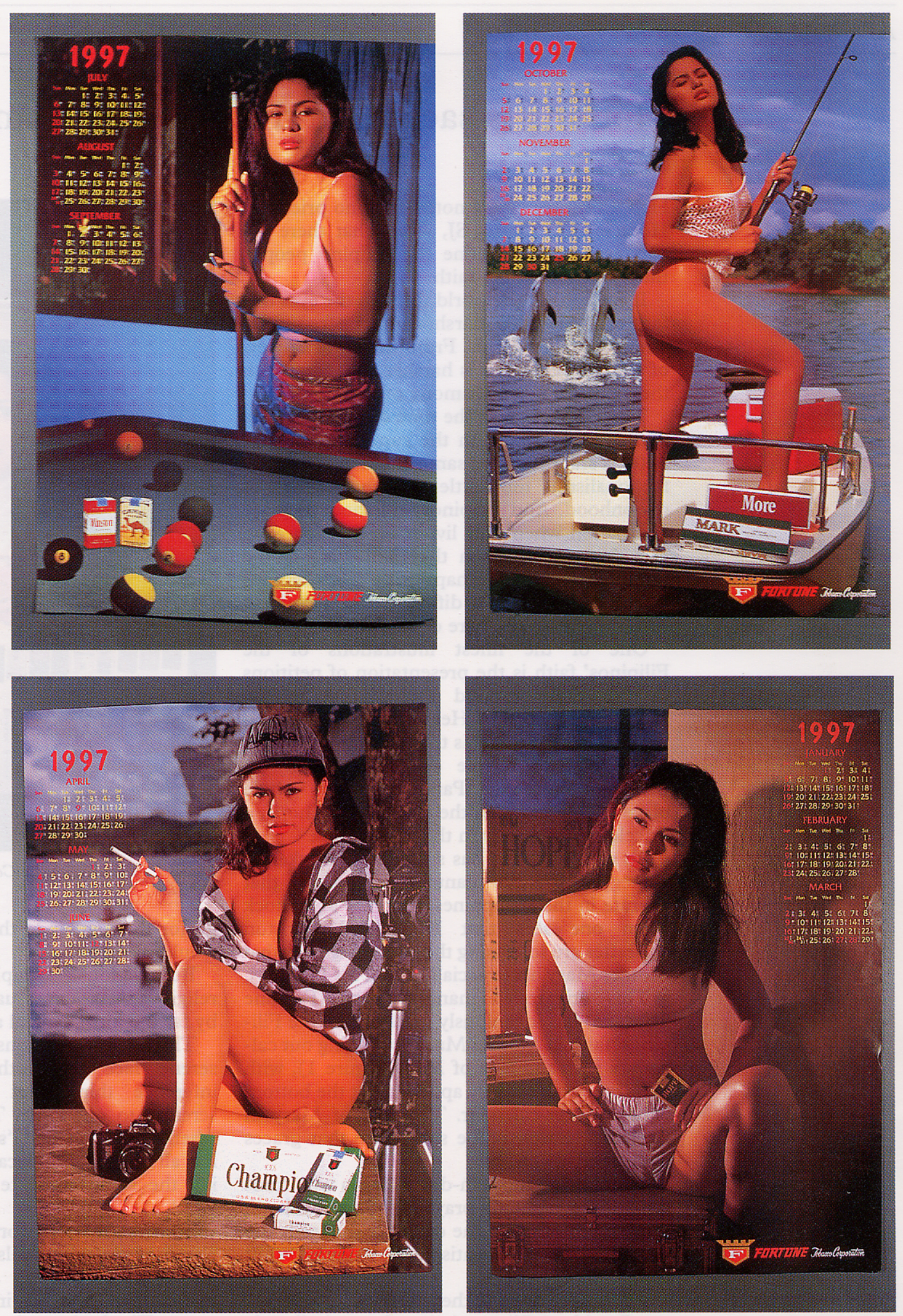

Figure 2 Fortune Tobacco calendars featuring "pin-up models".

well, no one takes things seriously, not even serious things.

There is a deep end to this coping mechanism. The evil grows. Just like a man with cancer would not see a doctor, until it's too late.

Does God take vengeance? Does God mind when His unsuspecting faithful are nothing but market statistics, cleverly entrapped, silent as lambs being led to slaughter? But, wait, does not God manifest His will through men?
Who can stop this? One can only hope that it will be the self-regulating body that screens advertisements before they are released. And we can only hope that the princes of the church will see in due time the harm that comes to the unsuspecting Filipino faithful every time he kneels down in front of the family altar.

If the cigarette maker can use symbols of God's loving kindness and man's basest instincts for its own earthly purpose, what can the next generation of Filipinos expect to see? If the 
merchants of death are so willing to touch the very soul of a Filipino as he lifts himself to his God, trivialise his religiosity, and capitalise on his weakness, how truly low can we expect the cigarette makers and marketers to go? If nothing is sacred to them, when is enough, enough?

WILFREDO G VILLANUEVA

17 Durian Road, Pilar Village, Las Pinas City 1740, Philippines

Mr Villanueva, a devout Catholic, told us that he began smoking cigarettes when exposed to "earthly things" in college. He stopped smoking 25 years ago, and is now a member of Smoke-Free Philippines. Through his experience with smoking, -1 he believes that cigarettes not only weaken one's defences against disease, but one's spirituality as well.

A photograph of the 1994 Madonna calendar $\vec{\Rightarrow}$ appeared in an earlier article in Tobacco Control: Chapman S, Stanton H. Philippines:등 poverty, powerlessness, and Our Lady of Cigarettes. Tobacco Control 1994;3:200-1.-ED

\section{Fuel pump promos}

Marlboro and other cigarette brands have found a new meaning for the phrase "pump priming money". The cigarette advertisements

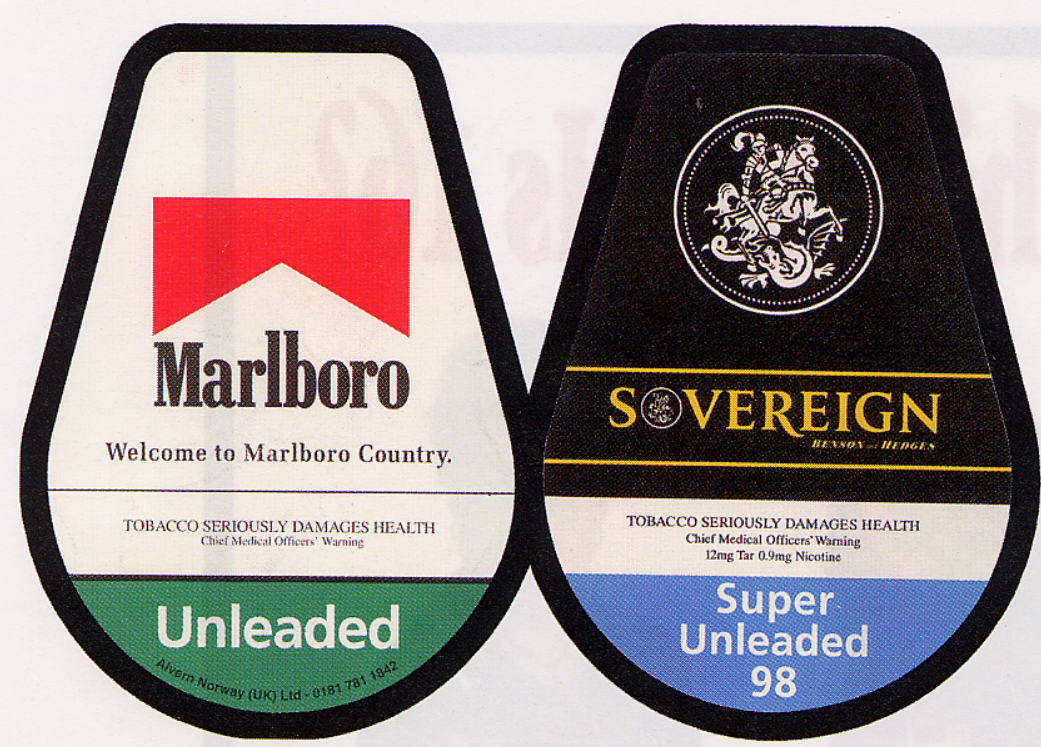

Figure 1 Fuel pump advertisements for Marlboro and Sovereign cigarettes. (Photo credit: Fudith Cohen.)

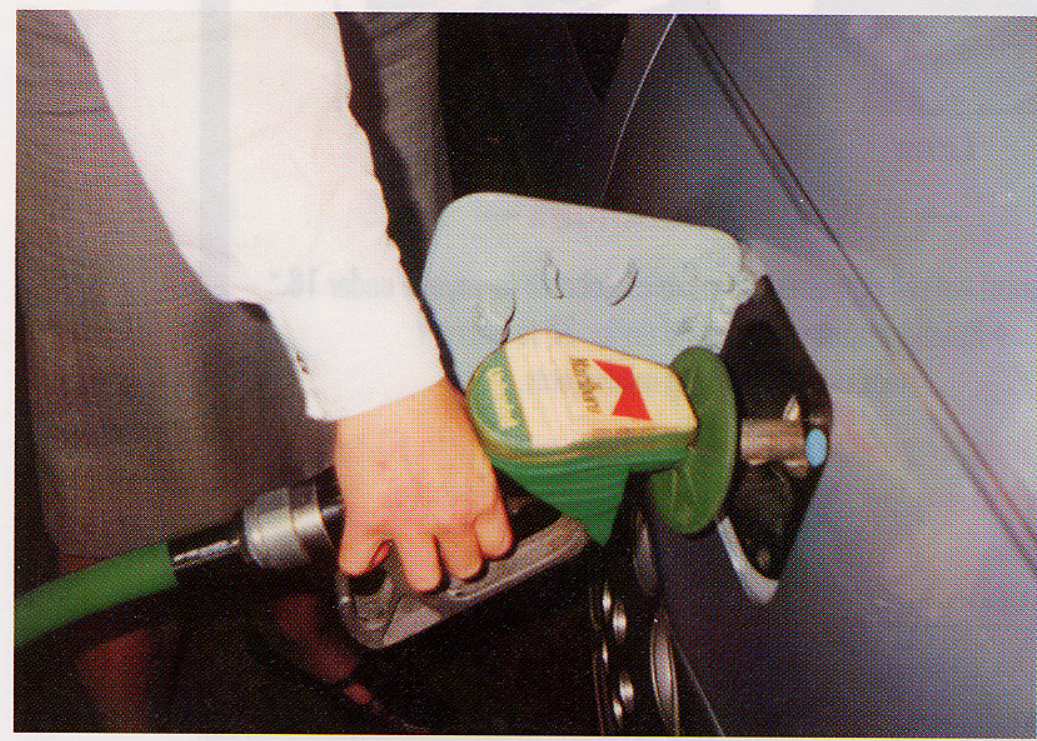

Figure 2 A Marlboro advertisement affixed to a fuel pump. (Photo credit: Fudith Cohen.) shown in the figures were at a Fina petrolo (gasoline) filling station in Nottingham, England in June 1997. This form of marketing has high reach: Alvern-Norway (UK) Ltd esti- $\mathbb{\Phi}_{\mathbb{D}}$ mates that about two million people see an 3 advertisement on one of their nozzles each day. 뜬 It is also potentially a very effective site for $\vec{\theta}$ advertising, as their own literature spells out.

"Our advertisers are communicating their message on a one-to-one basis directly to their end-customer, in an undisturbed environment for an average of two to three minutes at a time $\overline{\bar{o}}$ when the customer has little alternative but to $\stackrel{2}{\circ}$

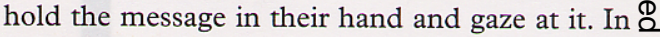
many cases, there is an opportunity to react or $\overrightarrow{\vec{A}}$ purchase just thirty seconds away, in the $\frac{0}{3}$ forecourt shop." (Alvern-Norway, written communication, 7 July 1997) [The forecourt is the front area of the filling station where the fuel pumps stand.]

This marketing company hit on the idea of selling advertising space on the nozzles of fuel $ᄋ$ pumps five years ago. They now operate in 16 음 countries worldwide. Alvern-Norway has agreements with 22 oil companies and is $\frac{\text { 을 }}{3}$ currently negotiating with $\mathrm{BP}$, Shell, and Mobil. There are 5500 sites carrying advertising in the United Kingdom: they expect cover- 3 age to reach 9000 by the end of 1997. Recognising the number of potential advertising sites, it has now registered as Alvern Forecourt Media Ltd.

The lowest total awareness figures obtained $\stackrel{N}{\sigma}$ by independent research commissioned by $N$ Alvern to assess the impact of their forecourt $N$ campaigns were $50 \%$. Total awareness in Nor- 으 way was $81 \%$. Spontaneous awareness of o advertising for the Texas National Lottery in the USA was $31 \%$ whereas total awareness reached $71 \%$. Alvern states that its own research shows that forecourt advertising can $\frac{\vec{D}}{\mathbb{D}}$ improve brand awareness, generate an increase $\frac{\rho}{\mathbb{D}}$ in sales, and improve the distribution of a $\cong$ product. Their material concludes: "Advertising in a forecourt environment provides an 8 opportunity to advertise to a captive market and specifically to a mature audience. As the customer holds the advertising message for $2-3 \stackrel{?}{?}$ minutes, the opportunity to see the advertising message is immense." 
Alvern Forecourt Media equip the sites, provide and maintain the units installed on the nozzles, and secure and organise the advertising. The oil companies provide the pump nozzles and approve the artwork. The funds are split equally between them. Alvern also arranges counter space for leaflets, competition entry boxes, in-store floor graphics, and printing on the reverse of till receipts and debit/credit card vouchers.

Costs depend on the number of sites, the oil company, and the location. Prices include production and printing costs but are for a minimum of 175 sites. Motorway filling stations, which have an average of 42 nozzles and a higher than average throughput, are the most expensive at $£ 250(\$ 375)$ per site per month. Asda supermarket costs $£ 230$ (\$345) per site per month but all 125 sites must be included. Esso and Texaco garages, with 20 nozzles per site, cost $£ 60$ (\$90) per site per month. Other companies, with an average of 17 nozzles, cost $£ 50(\$ 75)$ per site per month.
The only good news is that it is illegal in the United Kingdom for children aged under 16 to use the fuel pumps (a law which is adhered to), although the back seats of cars are usually level with the pumps and young children love watching the car being filled.

Twenty-nine customers are listed in the company's promotional material as having booked space and run campaigns on their medium in the past 12 months, including Gallaher Tobacco and Rothmans (which markets Marlboro and Raffles in the United Kingdom). Ironically, British filling stations all carry (small) signs by each pump that smoking is prohibited on the forecourt.

JENNIFER MINDELL

Department of Epidemiology E Public Health Imperial College School of Medicine at St. Mary's Norfolk Place, London W2 1PG, UK; email:j.mindell@ic.ac.uk

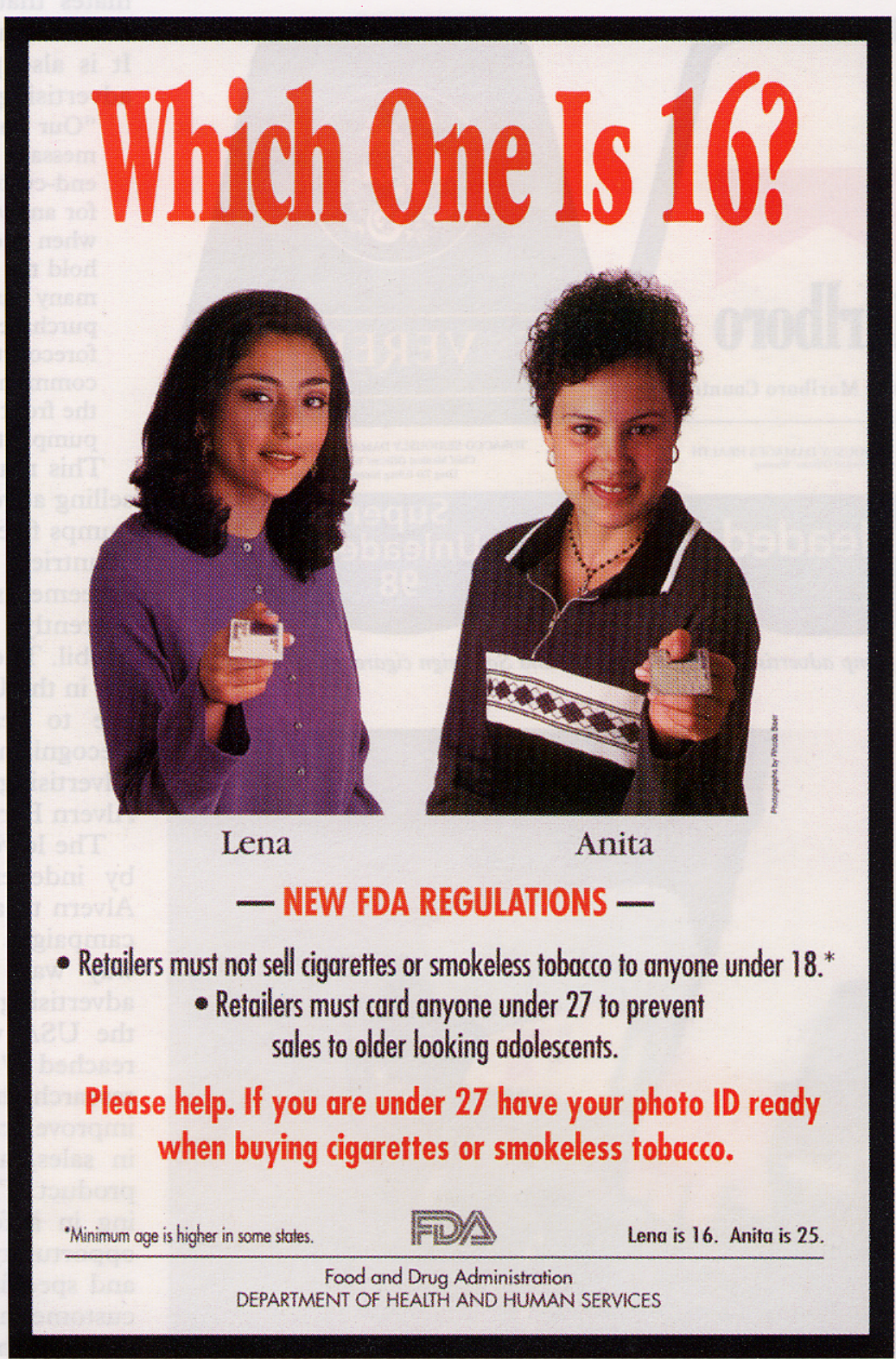

